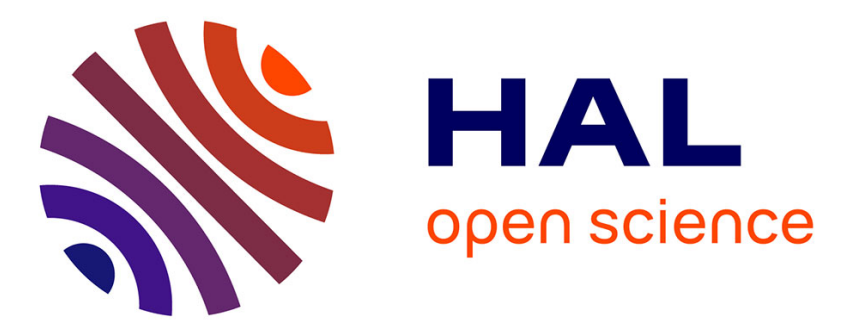

\title{
Sleep quality, duration and behavioral symptoms among 5-6-year-old children
}

E. Juulia Paavonen, Tarja Porkka-Heiskanen, Anja Riitta Lahikainen

\section{To cite this version:}

E. Juulia Paavonen, Tarja Porkka-Heiskanen, Anja Riitta Lahikainen. Sleep quality, duration and behavioral symptoms among 5-6-year-old children. European Child and Adolescent Psychiatry, 2009, 18 (12), pp.747-754. 10.1007/s00787-009-0033-8 . hal-00535159

\section{HAL Id: hal-00535159 \\ https://hal.science/hal-00535159}

Submitted on 11 Nov 2010

HAL is a multi-disciplinary open access archive for the deposit and dissemination of scientific research documents, whether they are published or not. The documents may come from teaching and research institutions in France or abroad, or from public or private research centers.
L'archive ouverte pluridisciplinaire HAL, est destinée au dépôt et à la diffusion de documents scientifiques de niveau recherche, publiés ou non, émanant des établissements d'enseignement et de recherche français ou étrangers, des laboratoires publics ou privés. 


\title{
Sleep quality, duration and behavioral symptoms among 5-6-year-old children
}

\author{
E. Juulia Paavonen · Tarja Porkka-Heiskanen • \\ Anja Riitta Lahikainen
}

Received: 30 October 2008/ Accepted: 4 May 2009/Published online: 24 May 2009

(C) Springer-Verlag 2009

\begin{abstract}
The objective of the present study was to examine whether parent-reported short sleep duration and sleeping difficulties are related to behavioral symptoms among pre-school aged children. The study is a crosssectional survey of 297 families with 5-6-year-old children. The Sleep Disturbance Scale for children was used to measure sleep duration and sleeping difficulties, and the Child Behavior Checklist and Teacher's Report Form were used to measure attention problems, and internalizing and externalizing symptoms. In multivariate logistic regression models, short sleep duration was according to parental reports related to inattention (adjusted odds ratio 4.70, 95\% CI 1.58-14.00), internalizing (adjusted odds ratio 3.84, 95\% CI 1.32-11.21), and total psychiatric symptoms (adjusted odds ratio 3.53 , 95\% CI 1.23-10.17) while according to teacher's reports it was almost significantly related to internalizing symptoms (adjusted odds ratio 4.20, 95\% CI 0.86-20.51). Sleeping difficulties were strongly related to all subtypes of psychiatric symptoms according
\end{abstract}

\section{E. J. Paavonen $(\varangle)$}

Child and Adolescent Mental Health, National Institute for Health and Welfare, P.O. Box 30, Lintulahdenkuja 4, 00271 Helsinki, Finland

e-mail: juulia.paavonen@helsinki.fi

\section{E. J. Paavonen}

Child Psychiatry, Hospital for Children and Adolescents, Institute of Clinical Medicine, University of Helsinki,

Helsinki, Finland

T. Porkka-Heiskanen

Institute of Biomedicine, University of Helsinki,

Helsinki, Finland

A. R. Lahikainen

Department of Social Research,

University of Tampere, Tampere, Finland to parental reports (adjusted odds ratios ranging from 6.47 to 11.71) and to externalizing symptoms according to teachers' reports (adjusted odds ratio 7.35, 95\% CI 1.6932.08). Both short sleep duration and sleeping difficulties are associated with children's behavioral symptoms. Intervention studies are needed to study whether children's behavioral symptoms can be reduced by lengthening sleep duration or improving sleep quality.

Keywords Child · Sleep disturbance $\cdot$ Sleep deprivation Sleep duration - Behavior · Psychiatric symptoms

\section{Introduction}

A growing number of epidemiological studies has linked children's sleeping difficulties with a variety of psychiatric symptoms such as depression, anxiety, externalizing problems and hyperactivity [2, 7, 15-17, 21, 22, 27, 28]. Much less is known about the association between sleep duration and psychiatric symptoms in children even though a vast amount of adult studies have clearly shown that sleep deprivation is related to psychiatric symptoms, and it affects mood more than cognitive functioning [23]. Sleep fragmentation causes similar behavioral symptoms to sleep deprivation [29]. Although it seems likely that children's mood and behavior are also affected by sleep deprivation, it is not clear whether the results from adult studies can be directly extrapolated to children. First, inadequate sleep may have qualitatively different consequences among children as compared to adults. Dahl [9], for example, suggested that inadequate sleep may paradoxically manifest in children as hyperactivity, attention problems, irritability and emotional instability as well as a low threshold for frustration and distress. In adults, tiredness, 
depressiveness, and decreased vigilance are more typical symptoms of sleep deprivation [10]. Second, inadequate sleep may have quantitatively different consequences among children, as behavioral control is still developing and the compensatory mechanisms are immature. As a result, children may be more prone to the effects of sleep deprivation than adults. For example, the association between neurocognitive functioning and sleep quality has been reported to be the strongest among the youngest children [25].

The effects of children's sleep deprivation can be best studied in experimental settings, but apart from attention such studies have not included behavioral outcomes. Fallone et al. [12] showed that one-night partial sleep restriction was related to attention problems, while the increases in hyperactivity and behavioral symptom scores did not reach statistical significance. Later, they confirmed this finding by showing that sleep restriction increased teacher-rated attention problems and academic problems [13]. Sadeh et al. [26] reported that sleep extension by an hour improved children's working memory and attention as measured by a visual digit span test. Among adolescents, experimental sleep restriction has also been linked with tiredness $[4,5]$ and among school-aged children it has been related to cognitive deficits $[13,24]$. As there are no experimental studies to investigate the effects of sleep deprivation on behavior, and exposing young children to long sleep-deprivation protocols may be limited for ethical reasons; the importance of adequate sleep duration and sleep quality needs to be studied in epidemiological settings as well.

Four previous epidemiological studies have used measurements of average sleep duration to characterize the potential effects of sleep deprivation. These studies have been based either on parent-reported or actigraphically measured sleep duration and its comparison to various indicators of psychiatric symptoms. Wolfson and Carskadon [30] associated parent-reported short sleep duration with depressiveness in 13-19-year-old adolescents and Smedje et al. [28] with behavioral problems in 6-8-year-old children. Two studies have assessed sleep duration using actigraphs and compared it to behavioral symptoms. Aronen et al. [2] reported a negative correlation between actigraphically measured sleep duration and behavioral/internalizing symptoms in 7-12-year-old children. Nixon et al. [20] reported that short sleep duration $(<10 \mathrm{pt} ; 9.0 \mathrm{~h})$ in 7 -year-old children was related to emotional instability. Sadeh et al. [25] associated sleep fragmentation with behavioral problems, but they did not report any findings related to sleep duration. To our knowledge, no previous studies have studied the association of short sleep and psychiatric symptoms among children $<6$ years old.
The current study was set out to establish whether short sleep duration or sleeping difficulties are associated with behavioral symptoms or tiredness in 5-6-year-old children. Our hypothesis was that both short sleep and sleeping difficulties are related to inattention, internalizing, and externalizing symptoms and tiredness.

\section{Methods}

Study sample

A population-based random sample was collected. The sample was randomly extracted by the Population Register Center. The sampling frame included all families in three middle-sized university cities with 5-6-year-old children born between 1 January 1997 and 31 December 1998. The initial sample covered 428 families. An information letter was sent to these parents. They were then contacted by phone to determine whether they wanted to participate; 64 (15.0\%) families were not reached by phone and $33(7.7 \%)$ refused to participate. Questionnaires were thus sent to 331 families. Following reminders, 307 families returned the questionnaires, and thus the response rate was $95.6 \%$ (307/ 321). Families with severe participation problems were excluded; three families due to child's severe handicap, three families due to parents poor/no knowledge of the language, one family due to severe parental alcohol problems, and three families that had moved out of town. The final sample therefore consisted of 297 families.

\section{Sleep disturbances}

The parents filled in a 26-item sleep questionnaire (the Sleep Disturbance Scale for Children, SDSC) that has a high internal consistency (0.79), and re-test reliability (0.71) [3]. There is one question concerning sleep duration with the response alternatives of 9-11, 9-8, 7-8, 5-7, and $<5 \mathrm{~h}$. Long sleepers were defined as those who were rated to sleep 9-11 h, and short sleepers were rated to sleep 8-9, $7-8$, or $<7 \mathrm{~h}$. Another question concerned sleep latency with the response alternatives $<15,15-30,30-45,45-60$, and $>60 \mathrm{~min}$. The other items covered various sleeping difficulties and for these items five response alternatives are given ("never", "occasionally, <1-2 times/month", "sometimes, 1-2 times per week", "often, 3-5 times per week", "always"). A total score and six subscale scores are calculated: disorders of initiating and maintaining sleep (DIMS), sleep breathing disorders (SBD), disorders of arousal (DA), sleep-wake transition disorders (SWTD), disorders of excessive somnolence (DES), and sleep hyperhydrosis (SHY). In the present article, we studied the sleeping difficulties total score and all the subscale scores 
as well as four items concerning tiredness (dichotomized at $\leq 1-2$ months vs. more). The subscale scores were calculated if less than $20 \%$ of the information was missing on the corresponding scale ( 3 cases per scale were excluded because of this criterion). The total score was dichotomized at 39 points as suggested originally by Bruni et al. [3], which was the 74 th percentile in the present sample $(74.4 \%$ of the cases had $\leq 39$ points). This cut-off has a sensitivity of 0.89 and specificity of 0.74 when the cases with sleep disturbances were determined in a clinical evaluation [3]. The other subscale scores were dichotomized at the 75 th percentile.

\section{Behavioral symptoms}

To report children's psychiatric symptoms, the parents filled in the Achenbachs' Child Behavior Checklist (CBCL 6/18) and the day-care teachers filled in the Teacher's Report Form (TRF 6/18). Both of these are standardized and well-documented questionnaires on children's behavior and mental health, with more than 100 items, each with three response alternatives [1]. A total score, internalizing and externalizing scores, and eight sub-scale scores are calculated from the responses. The cut-off values for deviant and borderline behavior have been previously defined by Achenbach, but because the sample was normative, there was only a small amount of children exceeding these cut-offs. Therefore, the CBCL raw scores were categorized using the 90th percentile as the cut-off value (attention score $\geq 5$ points, $n=26$, $8.9 \%$; externalizing score $\geq 15$ points, $n=28,9.6 \%$; internalizing score $\geq 10$ points, $n=24,8.2 \%$; total score $\geq 39$ points; $n=31,10.6 \%$ ). The TRF raw scores were categorized similarly (attention score $\geq 19$ points, $n=13$, $10.3 \%$; internalizing score $\geq 9$ points, $n=11,8.7 \%$; externalizing score $\geq 11$ points, $n=12,9.5 \%$; total score $\geq 47$ points; $n=12,9.5 \%$ ). In the figure, we used the $t$ scores for illustrative purposes. There were 292 cases with a completed CBCL (response rate 98.3\%), and 126 cases with a completed TRF (response rate $46.4 \%$ of those who attended day-care).

\section{Background information}

Finally, a wide array of background information concerning, for example, socio-economic status, family financial situation, and family life was collected. In this study, the potential confounding factors that were defined as family income, mother's and father's education, parental occupational status, family conflicts, and daycare arrangements were tested in multivariate models, and of them, we finally controlled for mother's education (when the mother's ratings were missing, we used father's ratings, $n=1$ ), and gender due to theoretical reasons. Control for the other putative confounding variables did not affect the findings. One-third ( $n=107,36.9 \%$ ) of the mothers belonged to the low education group (had not graduated from senior high school); $35.2 \%(n=102)$ of the mothers were in the intermediate group (some lower qualifications or matriculation examination only); $27.9 \%$ ( $n=81$ ) of the mothers were in the high education group (academic degree). There were 138 girls (46.8\%) and 157 boys $(53.2 \%)$.

\section{Statistical analysis}

To assess the effects of short sleep duration and sleeping difficulties, the Mann-Whitney $U$ test was used to compare the mean DES score or the psychiatric symptom scores in the two groups (short sleep vs. long sleep; no sleeping difficulties vs. sleeping difficulties). Cohen's $d$ was used as a measure of effect size. Pair-wise comparisons of the categorical variables were carried out using $X^{2}$ tests and if its assumptions were violated, Fischer's exact test was used. Finally, a set of hierarchical logistic regression analyses were carried out to control for confounding factors and to test the hypothesis that short sleep duration and sleeping difficulties are associated with psychiatric symptoms. Both crude odds ratios (OR) and adjusted odds ratios (AOR) were calculated. In the adjusted models, gender, and mother's educational attainment were controlled statistically. The dependent variables were the four psychiatric symptom scores in the CBCL and the TRF as dichotomized at the 90th percentile. The two explanatory variables were sleep duration and sleeping difficulties, and they were studied in separate models. Assumption testing was conducted to check for collinearity, multivariate outliers, zero cells, and standard errors for all model parameters with no violations being found. The statistical significance level was set at $P<0.05$ and $P<0.1$ was considered almost significant.

\section{Results}

Basic data

Most of the children slept more than $9 \mathrm{~h}(90.4 \%, n=253)$, but every tenth child slept $8-9$ h a night $(9.6 \%, n=27)$, and there was one case with a sleep duration of less than $7 \mathrm{~h}$ a night $(0.4 \%, n=1)$. The majority of the children fell asleep after $<15 \min (47.3 \%, n=130)$, or in $15-30 \mathrm{~min}$ $(44.0 \%, n=121)$, but almost every tenth of the children fell asleep in 30-45 $\min (7.3 \%, n=20)$, or in 45-60 min $(1.1 \%, n=3)$. In one case falling asleep took more than $1 \mathrm{~h}(0.4 \%)$. There were 11 cases with short sleep and no 
sleeping difficulties, and 16 cases with both sleeping difficulties and short sleep duration.

Sleep duration and tiredness

Short sleep duration was almost significantly related to the DES score $(6.8 \pm 1.6$ vs. $7.4 \pm 1.7 ; t$ test, $P=0.064)$. Particularly, it was almost significantly related to tiredness in the morning ("the child awakes in the morning feeling tired", $P=0.066$ ), but not awakening problems ("the child is unusually difficult to wake up in the morning", $P=0.298$ ), daytime tiredness ("the child experiences daytime somnolence", $P=0.745$ ) or sleep-attacks during the daytime ("the child falls asleep suddenly in inappropriate situations", $P=0.743$ ).

Sleep duration and psychiatric symptoms

The psychiatric symptom scores were significantly higher in children with short sleep duration as compared to other children (Table 1). According to parental reports, statistically significant differences were noted on attention $(P=0.024)$, internalizing $(P=0.034)$, and total scores $(P=0.015)$, and an almost significant difference was found on the externalizing symptoms subscale $(P=0.063)$. However, parental reports of short sleep duration were not related to any of the TRF subscale scores (all $P>0.266$ ).
Sleeping difficulties and psychiatric symptoms

As reported in the Table 1, sleeping difficulties were significantly related to inattention, internalizing, and externalizing symptoms and the total score as reported by the parents (all $P$ values $<0.001$ ). According to teachers' reports, sleeping difficulties were significantly related to internalizing symptoms $(P=0.031)$ and almost significantly to externalizing symptoms $(P=0.086)$ and the total score $(P=0.075)$. All the different forms of sleeping difficulties were significantly or almost significantly associated with the CBCL total score (all $P$ values $\leq 0.073$ ), but only DIMS $(P=0.026)$ and $\operatorname{SBD}(P=0.067)$ were related to the TRF total score (Table 2). Regarding the TRF subscale scores, DIMS was related to internalizing symptoms $(P=0.026)$, and SBD to inattention $(P=0.090)$ and externalizing symptoms $(P=0.013)$.

Multivariate models

Next, we conducted a series of logistic regression models to see whether short sleep duration and sleeping difficulties are associated with psychiatric symptoms when the confounding factors (sex, mother's educational attainment) were controlled for. We found that both short sleep duration and sleeping difficulties were significantly related to parent-reported psychiatric problems as defined by a CBCL raw score $>90$ th percentile (Table 3). Short sleep was

Table 1 Mean psychiatric symptom scores in children with long (9-11 h) and short (5-9 h) sleep duration and in children without sleeping difficulties (sleep disturbance score $<39$ ) and with sleeping difficulties (sleep disturbance score $\geq 39$ )

\begin{tabular}{|c|c|c|c|c|c|c|c|c|}
\hline & $\begin{array}{l}\text { Mean } \pm \text { SD } \\
n=251\end{array}$ & $\begin{array}{l}\text { Mean } \pm \text { SD } \\
n=27\end{array}$ & $P^{*}$ & Effect size $^{a}$ & $\begin{array}{l}\text { Low sleep } \\
\text { disturbance } \\
\text { score }(<39) \\
\text { Mean } \pm \text { SD } \\
n=192\end{array}$ & $\begin{array}{l}\text { High sleep } \\
\text { disturbance } \\
\text { score }(\geq 39) \\
\text { Mean } \pm \text { SD } \\
n=98\end{array}$ & $P^{*}$ & $\begin{array}{l}\text { Effect } \\
\text { size }^{a}\end{array}$ \\
\hline \multicolumn{9}{|l|}{ CBCL } \\
\hline Attention & $2.4 \pm 2.1$ & $3.5 \pm 2.4$ & 0.024 & 0.49 & $1.9 \pm 1.7$ & $3.8 \pm 2.4$ & $<0.001$ & 0.86 \\
\hline Internalizing symptoms & $4.0 \pm 3.9$ & $6.2 \pm 5.5$ & 0.034 & 0.52 & $3.0 \pm 3.0$ & $6.6 \pm 5.1$ & $<0.001$ & 0.87 \\
\hline Externalizing symptoms & $7.6 \pm 5.8$ & $10.1 \pm 7.4$ & 0.063 & 0.41 & $6.2 \pm 4.8$ & $11.1 \pm 7.3$ & $<0.001$ & 0.78 \\
\hline \multirow[t]{2}{*}{ Total psychiatric symptoms } & $19.2 \pm 13.4$ & $27.4 \pm 17.5$ & 0.015 & 0.58 & $15.5 \pm 10.5$ & $29.0 \pm 16.6$ & $<0.001$ & 0.94 \\
\hline & $N=98$ & $N=14$ & & & $n=80$ & $n=37$ & & \\
\hline \multicolumn{9}{|l|}{ TRF } \\
\hline Attention & $6.0 \pm 7.2$ & $8.9 \pm 10.8$ & 0.266 & 0.37 & $5.9 \pm 7.1$ & $8.3 \pm 9.9$ & 0.468 & 0.29 \\
\hline Internalizing symptoms & $3.7 \pm 3.8$ & $5.0 \pm 5.3$ & 0.520 & 0.32 & $3.5 \pm 4.4$ & $4.7 \pm 3.9$ & 0.031 & 0.28 \\
\hline Externalizing symptoms & $4.3 \pm 6.2$ & $5.4 \pm 10.0$ & 0.589 & 0.17 & $3.3 \pm 5.1$ & $7.0 \pm 8.6$ & 0.086 & 0.52 \\
\hline Total psychiatric symptoms & $16.3 \pm 17.1$ & $22.6 \pm 27.8$ & 0.628 & 0.33 & $14.9 \pm 15.9$ & $23.5 \pm 23.7$ & 0.075 & 0.45 \\
\hline
\end{tabular}

CBCL Child Behavior Checklist; TRF Teacher's Report Form

* Mann-Whitney $U$ test

a Cohen's $d$ 
Table 2 Proportion of children with high parent- or teacher-reported psychiatric symptoms total score in groups with low and high sleep disturbance scores (dichotomized at the 75th percentile)

\begin{tabular}{lcccc}
\hline & $\begin{array}{l}\text { CBCL } \\
\text { Total problems } \\
\geq 90 \mathrm{pt} \%(n)^{\mathrm{a}}\end{array}$ & & $\begin{array}{l}\text { TRF } \\
\text { Total problems } \\
\geq 90 \mathrm{pt} \%(n)^{\mathrm{a}}\end{array}$ & $P^{*}$ \\
\hline Low DIMS & $7.6(18)$ & & $6.3(6)$ & \\
High DIMS & $25.0(13)$ & $<0.001$ & $23.8(5)$ & 0.026 \\
Low SBD & $8.0(19)$ & & $7.1(7)$ & \\
High SBD & $21.6(11)$ & 0.004 & $22.2(4)$ & 0.067 \\
Low DA & $7.4(18)$ & & $8.7(9)$ & \\
High DA & $28.3(13)$ & $<0.001$ & $14.3(2)$ & 0.619 \\
Low SWTD & $9.1(21)$ & & $10.6(10)$ & \\
High SWTD & $17.2(10)$ & 0.073 & $4.5(1)$ & 0.687 \\
Low DES & $8.1(20)$ & & $10(10)$ & \\
High DES & $25(11)$ & 0.002 & $5.9(1)$ & 0.502 \\
Low SHY & $7.6(17)$ & & $8.9(8)$ & \\
High SHY & $19.7(13)$ & 0.005 & $11.1(3)$ & 0.714 \\
\hline
\end{tabular}

CBCL Child Behavior Checklist; TRF Teacher's Report Form; DIMS disorders of initiating and maintaining sleep; $S B D$ sleep breathing disorders; $D A$ disorders of arousal; SWTD sleep-wake transition disorders; DES disorders of excessive somnolence; SHY sleep hyperhydrosis

* Chi-square test

a The percentage and $n$ indicate how many of those with low/high sleep disturbance score had a high symptoms score

significantly related to inattention (AOR $4.70,95 \%$ CI 1.58-14.00), internalizing symptoms (AOR 3.84, 95\% CI 1.32-11.21), and total psychiatric symptoms (AOR 3.53, 95\% CI 1.23-10.17), and it was almost significantly associated with externalizing problems (AOR 2.89, 95\% CI 0.95-8.79). Sleeping difficulties, on the other hand, were strongly associated with each of the subscale scores that were studied (AOR's ranging from 6.47 to 11.71). According to teachers' reports, parent-reported short sleep was almost significantly related to internalizing symptoms (AOR 4.20, 95\% CI 0.86-20.51). Sleeping difficulties, on the other hand, were significantly related to teacherreported externalizing symptoms (AOR 7.35, 95\% CI $1.69-32.08)$.

\section{Moderation}

To study whether there are any interactions between short sleep duration and sleeping difficulties, we made a plot where all children were classified into four groups. First, the children with short sleep duration were divided into two groups: those who had no sleeping difficulties $(n=11)$ and those who had sleeping difficulties $(n=16)$. Then the children with long sleep duration were grouped similarly; there were 174 individuals without sleeping difficulties and
79 individuals with sleeping difficulties. As shown in the Fig. 1, the individuals who had both short sleep duration and sleeping difficulties had the highest symptoms scores, while the lowest scores were found in those who slept more and had no sleeping difficulties. On the basis of the post hoc tests (Table note), the statistically significant differences seemed to reflect mostly the presence of sleeping difficulties. We then performed some subgroup analyses and found that the individuals with short sleep and sleeping difficulties had higher scores than those who had sleeping difficulties only (attention score 3.6 vs. 4.7, $P=0.044$; internalizing score 6.2 vs. $9.3, P=0.043$; total score 27.3 vs. $37.1, P=0.049$ ). When the individuals with sleeping difficulties were excluded, we could not observe respective trends; the individuals with short sleep did not differ from those who slept more. However, as the $N$ was rather small in the short sleep group, these findings need to be confirmed in future studies.

\section{Discussion}

The present study showed that both short sleep duration and sleeping difficulties are related to psychiatric symptoms as reported by the parents and the teachers. Dahl [9] has previously suggested inadequate sleep in children to be associated with attention problems, irritability and emotional instability as well as low threshold for frustration and distress. In the line of this, we found that both short sleep and sleeping difficulties were related to both inattention and externalizing symptoms according to both informants.

Two previous epidemiological studies have shown that school-aged children's behavioral symptoms are related to short sleep duration [2,28], but as far as we know, younger children have not been studied previously (even though there are studies on young children's sleeping difficulties and behavioral problems, there are no studies on sleep duration and behavioral problems). Among older children and similar to our findings, short sleep duration has been linked with depressiveness $[2,30]$ and behavioral problems $[2,28]$. Sleep quality, well-defined bedtimes and feeling rested at school has been associated with better functioning at school [19] and an early start-time for school has been linked with daytime sleepiness and attention problems [6, 11]. Sleep impairment and its effects on school performance have been reviewed in detail by Wolfson and Carskadon [31] and those who perform well at school tend to go to bed earlier, sleep more, and have more regular sleep/wake rhythms. However, one large epidemiological study reported contrasting findings; they linked long sleep duration with behavioral problems, but the study concerned adolescents which may go some way to explain this discrepancy [27]. 
Table 3 A multivariate hierarchical logistic regression models to study whether short sleep and sleep disturbances are associated with parentreported psychiatric symptoms

\begin{tabular}{|c|c|c|c|c|c|c|c|c|}
\hline & $\begin{array}{l}\text { Long sleep } \\
\left(\geq 9 \text { h) } \%(n)^{\dagger}\right.\end{array}$ & $\begin{array}{l}\text { Short sleep } \\
(<9 \text { h }) \%(n)^{\dagger}\end{array}$ & $\begin{array}{l}\text { OR }(95 \% \text { CI }) \\
{[P]^{\#}}\end{array}$ & $\begin{array}{l}\text { AOR } \\
(95 \% \mathrm{CI})[P]^{*}\end{array}$ & $\begin{array}{l}\text { Low sleep } \\
\text { disturbance } \\
\text { score } \\
(<39) \%(n)^{\dagger}\end{array}$ & $\begin{array}{l}\text { High sleep } \\
\text { disturbance } \\
\text { score }(\geq 39) \%(n)^{\dagger}\end{array}$ & $\begin{array}{l}\text { OR } \\
(95 \% \mathrm{CI})[P]^{\#}\end{array}$ & $\begin{array}{l}\text { AOR } \\
(95 \% \mathrm{CI})[P]^{*}\end{array}$ \\
\hline \multicolumn{9}{|l|}{ CBCL } \\
\hline $\begin{array}{l}\text { Attention } \\
\geq 90 \mathrm{pt}\end{array}$ & 7.2 (18) & $25.9(7)$ & $\begin{array}{l}4.53 \\
(1.69-12.14) \\
{[0.001]}\end{array}$ & $\begin{array}{l}4.70 \\
(1.58-14.00) \\
{[0.005]}\end{array}$ & $3.6(7)$ & 19.4 (19) & $\begin{array}{l}6.36 \\
(2.57-15.72) \\
{[<0.001]}\end{array}$ & $\begin{array}{l}6.47 \\
(2.56-16.34) \\
{[<0.001]}\end{array}$ \\
\hline $\begin{array}{l}\text { Internalizing } \\
\geq 90 \mathrm{pt}\end{array}$ & $6.8(17)$ & $22.2(6)$ & $\begin{array}{l}3.93 \\
(1.40-11.04) \\
{[0.006]}\end{array}$ & $\begin{array}{l}3.84 \\
(1.32-11.21) \\
{[0.014]}\end{array}$ & $2.1(4)$ & $20.4(20)$ & $\begin{array}{l}12.05 \\
(3.99-36.40) \\
{[<0.001]}\end{array}$ & $\begin{array}{l}11.71 \\
(3.83-35.81) \\
{[<0.001]}\end{array}$ \\
\hline $\begin{array}{l}\text { Externalizing } \\
\geq 90 \mathrm{pt}\end{array}$ & $8.4(21)$ & $22.2(6)$ & $\begin{array}{l}3.13 \\
(1.14-8.06) \\
{[0.021]}\end{array}$ & $\begin{array}{l}2.89 \\
(0.95-8.79) \\
{[0.061]}\end{array}$ & $3.6(7)$ & $21.4(21)$ & $\begin{array}{l}7.21 \\
(2.94-17.65) \\
{[<0.001]}\end{array}$ & $\begin{array}{l}6.59 \\
(2.65-16.43) \\
{[<0.001]}\end{array}$ \\
\hline $\begin{array}{l}\text { Total } \\
\text { problems } \\
\geq 90 \mathrm{pt}\end{array}$ & $9.2(23)$ & $25.9(7)$ & $\begin{array}{l}3.47 \\
(1.33-9.08) \\
{[0.008]}\end{array}$ & $\begin{array}{l}3.53 \\
(1.23-10.17) \\
{[0.020]}\end{array}$ & $3.6(7)$ & $24.5(24)$ & $\begin{array}{l}8.57 \\
(3.54-20.75) \\
{[<0.001]}\end{array}$ & $\begin{array}{l}8.19 \\
(3.32-20.24) \\
{[<0.001]}\end{array}$ \\
\hline \multicolumn{9}{|l|}{ TRF } \\
\hline $\begin{array}{l}\text { Attention } \\
\geq 90 \mathrm{pt}\end{array}$ & $8.2(8)$ & $14.3(2)$ & $\begin{array}{l}1.88 \\
(0.36-9.89) \\
{[0.452]}\end{array}$ & $\begin{array}{l}1.67 \\
(0.29-9.59) \\
{[0.567]}\end{array}$ & $7.5(6)$ & $16.2(6)$ & $\begin{array}{l}2.39 \\
(0.71-7.98) \\
{[0.148]}\end{array}$ & $\begin{array}{l}2.09 \\
(0.60-7.31) \\
{[0.247]}\end{array}$ \\
\hline $\begin{array}{l}\text { Internalizing } \\
\geq 90 \mathrm{pt}\end{array}$ & $7.1(7)$ & 21.4 (3) & $\begin{array}{l}3.55 \\
(0.80-15.74) \\
{[0.080]}\end{array}$ & $\begin{array}{l}4.20 \\
(0.86-20.51) \\
{[0.076]}\end{array}$ & $8.8(7)$ & 10.8 (4) & $\begin{array}{l}1.26 \\
(0.35-4.62) \\
{[0.722]}\end{array}$ & $\begin{array}{l}1.12 \\
(0.29-4.25) \\
{[0.870]}\end{array}$ \\
\hline $\begin{array}{l}\text { Externalizing } \\
\geq 90 \mathrm{pt}\end{array}$ & $8.2(8)$ & $14.3(2)$ & $\begin{array}{l}1.88 \\
(0.36-9.89) \\
{[0.452]}\end{array}$ & $\begin{array}{l}1.36 \\
(0.24-7.59) \\
{[0.728]}\end{array}$ & $3.8(3)$ & $21.6(8)$ & $\begin{array}{l}7.08 \\
(1.76-28.54) \\
{[0.002]}\end{array}$ & $\begin{array}{l}7.35 \\
(1.69-32.08) \\
{[0.008]}\end{array}$ \\
\hline $\begin{array}{l}\text { Total } \\
\text { problems }\end{array}$ & $7.1(7)$ & $14.3(2)$ & $\begin{array}{l}2.17 \\
(0.40-11.66)\end{array}$ & $\begin{array}{l}1.85 \\
(0.31-11.07)\end{array}$ & $6.2(5)$ & $16.2(6)$ & $\begin{array}{l}2.90 \\
(0.83-10.22)\end{array}$ & $\begin{array}{l}2.36 \\
(0.63-8.80)\end{array}$ \\
\hline$\geq 90 \mathrm{pt}$ & & & {$[0.358]$} & {$[0.502]$} & & & {$[0.086]$} & {$[0.200]$} \\
\hline
\end{tabular}

Bold values indicate $P<0.1$. In the adjusted models, we controlled for sex, and mother's education ("not graduated from senior high school", "some lower qualifications or matriculation examination only", "academic degree")

${ }^{\dagger}$ The percentage and $\mathrm{n}$ indicate how many of those with long/short sleep or low/high sleep disturbance score, had a high symptom score

\# $O R$ odds ratio; $X^{2}$ test

* AOR adjusted odds ratio, $N=273$ in the CBCL models; $N=111$ in the TRF models

* AOR adjusted odds ratio, $N=285$ in the CBCL models; $N=116$ in the TRF models

$C B C L$ child behavior checklist; TRF teacher report form

However, studies based on objective measurements on attention could not find any associations between sleep duration and concentration [19]. Meijer et al. [19] speculated that it might be related to the nature of the test used to measure children's concentration; long and more demanding tests might be needed to objectively show the effects of sleep deprivation and to overcome the compensatory mechanisms among children. This would be consistent with Randazzo et al. [24] who were able to show that partial sleep deprivation among 10-14-year-old children affects only the most complex tasks.

Quite interestingly, we found that short sleepers tended to be more tired than other children in the morning but not during the daytime. It has been speculated that daytime tiredness is not a typical symptom of sleep deprivation among young children [9], but there are no previous studies on short sleep duration and its influence on daytime tiredness in this age group; so further studies are needed to replicate our finding. One possibility is that the parents are 


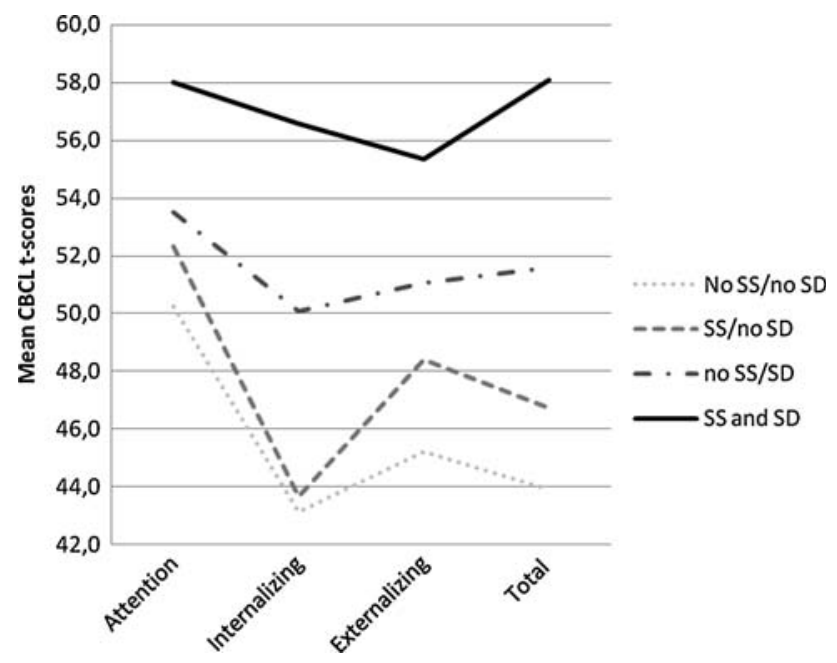

Fig. 1 Mean CBCL subscale scores in the children with long sleep and no sleeping difficulties (No SS/no SD), children with short sleep but no sleeping difficulties (SS/no SD), children with long sleep and sleeping difficulties (no SS/SD), and children with short sleep and sleeping difficulties (SS and SD). All the overall differences were statistically significant (Kruskall-Wallis test, all $P$ values $\leq 0.025^{*}$ ). *Tukey's test indicated that the differences stemmed from following pairs: attention No SS/no SD to SD $(P=0.086)$ and No SS/SD to SS and SD $(P=0.028)$; internalizing problems No SS/no SD to SD $(<0.001)$, No SS/no SD to SS and SD $(<0.001)$, SS to SD $(P=0.022), \mathrm{SS}$ and $\mathrm{SD}(P=0.002)$; externalizing problems: No $\mathrm{SS} / \mathrm{SD}$ to SD $(P=0.001)$; No SS/SD to SS and SD $(P=0.008)$; total score No SS/no SD to SD $(<0.001)$, No SS/SD to SS and SD $(<0.001)$. $C B C L$ child behavior checklist; TRF teacher report form

not aware of children's daytime tiredness, and future studies assessing children's tiredness should therefore also use self-reports.

Quite surprisingly we found that sleeping difficulties were not associated with teachers' reports of psychiatric symptoms as clearly as they were associated with parental reports. On one hand, the use of parent-reported measures for both sleep and behavior may cause bias resulting from the data being collected from the same source. On the other hand, the child's behavior at day-care can be affected by many factors that we did not control for (e.g. social relationships, bullying). However, the non-response rate of the teachers' reports was also high, and unfortunately it was not random; it was related to children's behavioral problems as reported by the parents. The children whose teachers did not fill in the TRF had a significantly higher CBCL total score $(P=0.009)$, which suggests that nonresponse bias affects our findings based on the TRF. Future studies should put extra effort to achieve high response rates to eliminate the non-response bias.

Our findings show that a valid association exists between parent reported sleep duration and sleeping difficulties and children's behavioral symptoms, but as the study was cross-sectional, it does not allow for conclusions on causal relationships. There are, however, positive criteria that can aid in the judgement of causality. Among other things, they include consistency of the findings in other studies and the biologic credibility of the hypothesis. As reviewed in the introduction, many previous studies concerning children have linked various sleeping difficulties with psychiatric symptoms suggesting that the findings are consistent across different studies. Even though the biological mechanism of how sleeping difficulties are linked with behavioral symptoms is not known, one putative mediating factor is sleep deprivation and/or sleep fragmentation, because experimental studies have consistently shown that they alter well-being and mood at least in adults. Sleeping difficulties and behavioral symptoms may also have similar origins: genetic [16] or environmental [14]. They both may also reflect underlying medical conditions. A recent study, for example, linked low serum ferritin levels with sleeping difficulties and more severe behavioral symptoms among children with ADHD [8]. Our findings call for further studies to track the potential effects of sleep deprivation and to assess (1) whether short sleep duration is related to psychiatric symptoms even when there are no sleeping difficulties, (2) whether sleeping difficulties are related to behavioral symptoms independent of sleep deprivation. Experimental or intervention studies are needed to study whether sleep duration or sleep fragmentation mediate the behavioral effects of sleeping difficulties.

The large sample size and the narrow age-range are major advantages in the present study. However, some methodological limitations are worth noticing. Sleep duration was measured on an ordinal scale, which means that the estimates may be inaccurate. Nevertheless, sleep duration $<9 \mathrm{~h}$ is insufficient for 5-6-year-olds and probably indicates sleep debt; it is less than the 2 nd percentile in the reference values for sleep duration in this age group [18]. In further studies, objective measurement methods or prospective sleep logs to study sleep duration could be used to confirm our findings. Another shortcoming is that we did not take into account the amount of daytime sleep. According to Iglowstein et al. [18], 8\% of 5-year-old and $5 \%$ of 6-year-old children are still napping. Napping should be taken into account in future studies, as it will increase the accuracy of the measurement of sleep duration.

Children's sleep duration has been decreasing in recent years [18], which may mean that a significant proportion of children suffer from sleep deprivation. Our study suggests that short sleepers have a 3.5-fold increase in risk for overall psychiatric symptoms, and both short sleep duration and sleeping difficulties are related to increased severity of psychiatric symptoms. More studies are needed to estimate how large a proportion of children suffer from the consequences of inadequate sleep. Data on sleep duration, however, does not allow for an estimation of how many of 
the short sleepers suffer from sleep deprivation; reported sleep duration does not necessarily represent physiological sleep need. All the short sleepers do not suffer from sleep deprivation, and a child with an average sleep duration can also suffer from sleep deprivation if his/her genetically determined sleep requirement is higher than average. An intervention study would be the most effective study design to recognize those who need more sleep: an individual with sleep deprivation will display improvements in behavior and well-being after lengthening of sleep duration. Furthermore, intervention studies are also needed to show how large an effect sleep deprivation can have on children's behavior and to assess how large a proportion of behavioral and attention problems for example at school could be reduced by simply increasing the children's sleep duration.

Acknowledgments This study was supported by the University of Tampere, Nokia, Elisa Communications, Signe and Ane Gyllenberg Foundation, Päivikki and Sakari Sohlberg's foundation, and the Academy of Finland.

\section{References}

1. Achenbach TM (1991) Child Behavior Checklist/4-18 and 1991 profile. Department of Psychiatry, University of Vermont, Burlington

2. Aronen ET, Paavonen EJ, Fjallberg M, Soininen M, Torronen J (2000) Sleep and psychiatric symptoms in school-age children. J Am Acad Child Adolesc Psychiatry 39:502-508

3. Bruni O, Ottaviano S, Guidetti V, Romoli M, Innocenzi M, Cortesi F et al (1996) The Sleep Disturbance Scale for Children (SDSC). Construction and validation of an instrument to evaluate sleep disturbances in childhood and adolescence. J Sleep Res 5:251-261

4. Carskadon MA, Harvey K, Dement WC (1981) Acute restriction of sleep in children. Percept Mot Skills 53:103-112

5. Carskadon MA, Harvey K, Dement WC (1981) Sleep loss in young adolescents. Sleep 4:299-312

6. Carskadon MA, Wolfson AR, Acebo C, Tzischinsky O, Seifer R (1998) Adolescent sleep patterns, circadian timing, and sleepiness at a transition to early school days. Sleep 21:871-881

7. Chervin RD, Dillon JE, Bassetti C, Ganoczy DA, Pituch KJ (1997) Symptoms of sleep disorders, inattention, and hyperactivity in children. Sleep 20:1185-1192

8. Cortese S, Konofal E, Bernardina BD, Mouren M-C, Lecendreux M (2009) Sleep disturbances and serum ferritin levels in children with attention-deficit/hyperactivity disorder. Eur Child Adolesc Psychiatry. doi: 10.1007/s00787-009-0746-8

9. Dahl RE (1996) The impact of inadequate sleep on children's daytime cognitive function. Semin Pediatr Neurol 3:44-50

10. Dinges DF, Pack F, Williams K, Gillen KA, Powell JW, Ott GE, Aptowicz C, Pack AI (1997) Cumulative sleepiness, mood disturbance, and psychomotor vigilance performance decrements during a week of sleep restricted to $4-5$ hours per night. Sleep 20:267-277

11. Epstein R, Chillag N, Lavie P (1998) Starting times of school: effects on daytime functioning of fifth-grade children in Israel. Sleep 21:250-256
12. Fallone G, Acebo C, Arnedt JT, Seifer R, Carskadon MA (2001) Effects of acute sleep restriction on behavior, sustained attention, and response inhibition in children. Percept \& Mot Skills 93:213229

13. Fallone G, Acebo C, Seifer R, Carskadon MA (2005) Experimental restriction of sleep opportunity in children: effects on teacher ratings. Sleep 28:1561-1567

14. Gregory AM, Caspi A, Moffitt TE, Poulton R (2006) Family conflict in childhood: a predictor of later insomnia. Sleep 29:1063-1067

15. Gregory AM, O'Connor TG (2002) Sleep problems in childhood: a longitudinal study of developmental change and association with behavioral problems. J Am Acad Child Adolesc Psychiatry 41:964-971

16. Gregory AM, Rijsdijk FV, Dahl RE, McGuffin P, Eley TC (2006) Associations between sleep problems, anxiety, and depression in twins at 8 years of age. Pediatrics 118:1124-1132

17. Hvolby A, Jorgensen J, Bilenberg N (2009) Parental rating of sleep in children with attention deficit/hyperactivity disorder. Eur Child Adolesc Psychiatry. doi: 10.1007/s00787-009-0750-z

18. Iglowstein I, Jenni OG, Molinari L, Largo RH (2003) Sleep duration from infancy to adolescence: reference values and generational trends. Pediatrics 111:302-307

19. Meijer AM, Habekothe HT, Van Den Wittenboer GL (2000) Time in bed, quality of sleep and school functioning of children. $\mathrm{J}$ Sleep Res 9:145-153

20. Nixon GM, Thompson JMD, Han DY, Becroft DM, Clark PM, Robison E et al (2008) Short sleep duration in middle childhood: risk factors and consequences. Sleep 31:71-78

21. Paavonen EJ, Aronen ET, Tamminen T, Räsänen E, Piha J, Moilanen I, Almqvist F (2002) Poor sleep and psychiatric symptoms at school: an epidemiological study. Eur Child Adolesc Psychiatry 11:10-17

22. Paavonen EJ, Solantaus T, Almqvist F, Aronen ET (2003) Four-year follow-up study of sleep and psychiatric symptoms in preadolescents: relationship of persistent and temporary sleep problems to psychiatric symptoms. J Dev Behav Ped 24:307-314

23. Pilcher JJ, Huffcutt AI (1996) Effects of sleep deprivation on performance: a meta-analysis. Sleep 19:318-326

24. Randazzo AC, Muehlbach MJ, Schweitzer PK, Walsh JK (1998) Cognitive function following acute sleep restriction in children ages 10-14. Sleep 21:861-868

25. Sadeh A, Gruber R, Raviv A (2002) Sleep, neurobehavioral functioning, and behavior problems in school-age children. Child Dev 73:405-417

26. Sadeh A, Gruber R, Raviv A (2003) The effects of sleep restriction and extension on school-age children: what a difference an hour makes. Child Dev 74:444-455

27. Shur-Fen Gau S (2006) Prevalence of sleep problems and their association with inattention/hyperactivity among children aged 6-15 in Taiwan. J Sleep Res 15:403-414

28. Smedje H, Broman JE, Hetta J (2001) Associations between disturbed sleep and behavioural difficulties in 635 children aged six to eight years: a study based on parents' perceptions. Eur Child Adolesc Psychiatry 10:1-9

29. Stepanski EJ (2002) The effect of sleep fragmentation on daytime function. Sleep 25:268-276

30. Wolfson AR, Carskadon MA (1998) Sleep schedules and daytime functioning in adolescents. Child Dev 69:875-887

31. Wolfson AR, Carskadon MA (2003) Understanding adolescents' sleep patterns and school performance: a critical appraisal. Sleep Med Rev 7:491-506 